\title{
Modeling of grain growth kinetics in complexly alloyed austenite
}

\author{
A. A. Vasilyev ${ }^{\dagger}$, S. F. Sokolov, D. F. Sokolov, N. G. Kolbasnikov \\ †vasilyev_aa@mail.ru
}

Peter the Great Saint Petersburg Polytechnic University, 29 Polytekhnicheskaya St., St. Petersburg, 195251, Russia

A quantitative model is presented to describe the kinetics of grain growth in complexly alloyed austenite. The model assumes that the activation energy of grain growth is proportional to the activation energy of bulk self-diffusion, which is calculated as a function of the chemical composition of the solid solution using the previously obtained formula. The empirical parameters of the model are determined on the basis of experimental data on the kinetics of isothermal grain growth in steels with the chemical composition varying in a wide range: $\mathrm{C}(0.05 \div 0.32)$, $\mathrm{Mn}(0.30 \div 1.88)$, $\mathrm{Si}(0.01 \div 0.29)$, $\mathrm{Ni}(0.0 \div 4.0), \mathrm{Cr}(0.0 \div 2.0)$, Mo $(0.0 \div 0.5)$, $\mathrm{Nb}(0.00 \div 0.05)$ available in the literature. The model allows one to obtain good agreement with the experiment for the considered steels in which the minimum $(\sim 79.7 \mathrm{~kJ} / \mathrm{mol})$ and maximum $(\sim 243.7 \mathrm{~kJ} / \mathrm{mol})$ values of the activation energy of grain growth differ by 3 times. The average absolute value of the relative error in calculating the grain size is about $11 \%$ that is comparable to the measurement error. Taking into account the influence of the chemical composition on the activation energy of grain growth, implemented in the developed model, it is possible to obtain agreement with the experiment without accounting for the solid-solution pinning of moving boundaries (the solute drag effect) requires a large number of additional empirical parameters (two exponential parameters for each alloying element). This result deserves further consideration from the physical viewpoint and verification on both simple carbon steels and steels with various quantities of $\mathrm{Mn}, \mathrm{Mo}$ and $\mathrm{Nb}$, which, according to literature, exert the strongest solute drag effect.

Keywords: austenite, grain growth, alloying, modeling.

\section{Introduction}

The normal grain growth exerts a notable effect on the austenite microstructure during hot rolling and strongly influences the microstructures of the heat affected zone in weld joints of steels. Owing to the practical significance of this phenomenon, it has attracted attention in many original works [1-17] and in monographs $[18,19]$. Grain growth is conventionally expressed [1-7] by the equation:

$$
D^{n}-D_{0}^{n}=A \exp \left(-\frac{Q_{G G}}{R T}\right) t,
$$

where $D$ is the grain size at time $t, D_{0}$ is the initial size, $Q_{G G}$ is the apparent activation energy of the process fitted to experimental data, $A$ and $n$ are the auxiliary parameters. According to various applications of Eq. (1), to fit the experimental results, $n$ commonly exceeds 2 corresponding to parabolic growth originally predicted in the classical work [20] for pure metals. Higher values of $n$ are ascribed to the growth retardation due to both phase precipitations (Zener's pinning [18]) and solute atoms of alloying elements or impurities (solute drag [21-23]). The corresponding activation energies has no certain physical meaning and strongly vary depending on the composition of the steel and the temperature range under study [2]. Other works [8-17] apply a more physically motivated approach where differential equations for the grain growth allow for the pinning of migrating boundaries by particles. However, when evaluating the mobility of boundaries, the apparent activation energy $Q_{G G}$ of their migration (activation energy of growth) is still treated as a fitting parameter independent of the chemical composition. It should be noted that all current models of this kind satisfactorily predict the austenite grain growth only with steel compositions previously used in their calibration.

According to the physics of diffusional rearrangements of atoms during the boundary migration of growing grains, the related activation energy should be comparable with the activation energy of grain boundary self-diffusion that, in turn, correlates with a similar characteristic for the bulk selfdiffusion (activation energy of self-diffusion, AESD), which is higher by about two times. It is notable that known results obtained by the radioactive tracer technique, which have been compiled by the authors [24], undoubtedly indicate that AESD in solid solutions of austenite depends on their chemical compositions. An empirical expression proposed in the last quoted paper enables accurate calculation of AESD in terms of quantities of alloying elements (C, Mn, $\mathrm{Si}, \mathrm{Ni}, \mathrm{Cr}, \mathrm{Mo}, \mathrm{Nb}, \mathrm{V}, \mathrm{Ti}$ ) most important for up-to-date steels. According to this expression, the addition of $\mathrm{Mn}, \mathrm{Si}$, $\mathrm{Mo}, \mathrm{Nb}$ or Ti may result in an essential increase of AESD whereas $\mathrm{Ni}, \mathrm{Cr}, \mathrm{V}$ and, especially, $\mathrm{C}$ reduce this term. With the mentioned proportionality of activation energy of the grain boundary self-diffusion to AESD kept in mind, it is advisable to employ the former with allowance for its dependence on the chemical composition in modeling the 
grain growth kinetics. This approach is the first to discard numerous auxiliary parameters conventionally related to the effect of the chemical composition on the solute drag mechanism [21-23].

The present paper formulates a model for grain growth in austenite depending on the elemental composition of the solid solution. Wide literature data have been used to determine the empirical model parameters relevant to the kinetics of the process in steels of various compositions.

\section{Model description}

The material energy reduction due to diminishing the whole boundary area is considered for a thermodynamic driving force of the grain growth. In case of pure metals or solid solutions the effective pressure $P_{G}$ moving the boundaries takes the form [18]:

$$
P_{G}=\alpha_{G} \frac{\gamma_{G B}}{D}
$$

where $D$ is the average grain size (volumetric diameter), $\gamma_{G B}$ is the specific energy of grain boundaries, $a_{G}$ is the coefficient of the order of unity. Allowing for the influence of the chemical composition on mobility of boundaries in alloyed austenite, the boundary velocity $V_{G}$ is expressed by:

$$
V_{G} \equiv V_{G}\left(T, Y_{A E}\right)=M_{G B}\left(T, Y_{A E}\right) P_{G}
$$

where $M_{G B}\left(T, Y_{A E}\right)$ specifies mobility, and $Y_{A E}=\left\{y_{C}, y_{M n}, y_{S i}, \ldots\right\}$ represents a set of average fractions of the sites of substitution and interstitial sublattices occupied, respectively, by the atoms of substitution alloying elements and carbon. Mobility term is expressed with allowance for entropy:

$$
M_{G B}\left(T, Y_{A E}\right)=M_{0} \exp \left(\frac{S_{G G}\left(Y_{A E}\right)}{R}\right) \exp \left(-\frac{Q_{G G}\left(Y_{A E}\right)}{R T}\right)
$$

where $Q_{G G}\left(Y_{A E}\right), S_{G G}\left(Y_{A E}\right)$ are activation energy and entropy of the grain growth, respectively, and $M_{0}$ is the empirical parameter, $R$ is the gaz constant and $T$ is the absolute temperature. According to [24], the activation entropy proportional to the corresponding energy will be treated with the fitting parameter $\beta_{G G}$, i. e. $S_{G G}\left(Y_{A E}\right)=\beta_{G G} Q_{G G}\left(Y_{A E}\right)$.

The present model presumes that $Q_{G G}\left(Y_{A E}\right)=a_{G G} Q_{S D}\left(Y_{A E}\right)$, where $Q_{S D}\left(Y_{A E}\right)$ is AESD in the solid solution of complexly alloyed austenite and $\alpha_{G G}$ is the empirical parameter. According to [24], the dependence of AESD on the chemical composition of the solid solution takes on the form:

$$
\begin{aligned}
Q_{S D}\left(Y_{A E}\right) & =311691-278242\left(1-\exp \left(-0.394 y_{\mathrm{C}}\right)\right)+ \\
& +88752 y_{\mathrm{Mn}}^{0.31}+22801 y_{\mathrm{Si}}-6490 y_{\mathrm{Cr}}+ \\
& +84864 y_{\mathrm{Mo}}^{0.65}-38575 y_{\mathrm{Ni}}^{0.3}-7298 y_{\mathrm{V}}+ \\
& +132594 y_{\mathrm{Nb}}^{0.263}+82128 y_{\mathrm{Ti}}^{0.401}(\mathrm{~J} / \mathrm{mol})
\end{aligned}
$$

and the rate of grain growth is expressed by:

$$
\frac{d D(t)}{d t}=2 V_{G}=K_{G}\left(T, Y_{A E}\right) \frac{1}{D(t)},
$$

where function $K_{G}\left(T, Y_{A E}\right)$ corresponds to Eqs. (2) - (4). At a constant temperature Eq. (6) is easily integrated and leads to the classic parabolic dependence [20]:

$$
D^{2}(t)-D_{0}^{2}=2 K_{G}\left(T, Y_{A E}\right) t
$$

where $D_{0}$ is the initial grain size.

In reality, however, the grain growth kinetics in austenite is complicated due to the retarding influence of various small particles of carbides, nitrides or carbonitrides, which remain in steel up to high temperatures. This effect (Zener's pinning) is taken into account in terms of the effective moving pressure [19]:

$$
P_{G}^{*}=P_{G}-P_{Z},
$$

where $P_{Z}$ is Zener's pressure:

$$
P_{Z}=\alpha_{Z} \gamma_{G B} \sum_{i} \frac{f_{P i}}{R_{P i}},
$$

expressed with volume fraction $f_{P i}$ and the average radius $R_{P i}$ for $i$-th type of particles, factor $\alpha_{z}$ is of the order of unity. With (8) and (9) kept in mind, equation:

$$
\frac{d D(t)}{d t}=K_{G}^{*}\left(T, Y_{A E}\right)\left[\frac{1}{D(t)}-\alpha_{Z}^{*} \sum_{i} \frac{f_{P i}}{R_{P i}}\right],
$$

expresses the grain growth rate, where $\alpha_{Z}^{*}=\alpha_{Z} / \alpha_{G}$, and $K_{G}^{*}(T)=\alpha_{G} \gamma_{G B} K_{G}(T)$.

Yet, it is difficult to make use of Eq. (10) since even in case of the single type of the barrier particles accurate determination of their dimensions and volume fraction [17] is rarely possible. That is why, to allow for Zener's pressure in empirical models, a virtually ultimate grain size $D_{\lim }$ is introduced:

$$
D_{\lim }=\frac{1}{\alpha_{Z}^{*}}\left(\sum_{i} \frac{f_{P i}}{R_{P i}}\right)^{-1},
$$

which value should be fitted to relevant experimental data. Making use of such an expedient, we express the growth rate, depending on chemical composition, as follows:

$$
\begin{aligned}
\frac{d D(t)}{d t} & =M_{0}^{*} \exp \left(\frac{\beta_{G G}^{*} Q_{S D}\left(Y_{A E}\right)}{R}\right) \times \\
& \times \exp \left(-\frac{\alpha_{G G} Q_{S D}\left(Y_{A E}\right)}{R T}\right)\left[\frac{1}{D(t)}-\frac{1}{D_{\lim }}\right] .
\end{aligned}
$$

Apart from $D_{\text {lim, }}$ Eq. (12) employs only three fitting parameters $\left(M_{0}^{*}, \alpha_{G G}, \beta_{G G}^{*}=\beta_{G G} \alpha_{G G}\right)$ determined in calibration on numerous steels of various chemical composition. It is notable that allowance for reduction of $Q_{S D}$ by certain alloying elements, mentioned in the introduction, enables the model to predict their accelerating effect on the grain growth.

\section{Model calibration, calculation results and their discussion}

The model has been calibrated with data on the isothermal grain growth kinetics for two industrial (S1 (DQSK), S2 (A36) $[9,25])$ and 8 laboratory (S3-S10 [3,11]) steels whose chemical compositions are listed in Table 1 (for brevity sake, they are shown with only two decimal digits). 
Table 1. Chemical compositions (wt.\%) of steels used to calibrate the model. $Q_{S D}$ is the activation energy of bulk self-diffusion calculated with Eq. (5) provided that all alloying elements are in solid solution (its minimum and maximum values are marked in bold).

\begin{tabular}{|c|c|c|c|c|c|c|c|c|c|c|c|}
\hline Steel & $\mathrm{C}$ & $\mathrm{Mn}$ & $\mathrm{Si}$ & $\mathrm{Ni}$ & $\mathrm{Cr}$ & $\mathrm{Mo}$ & $\mathrm{Nb}$ & $\mathrm{Al}$ & $\mathrm{N}$ & $Q_{S D}, \mathrm{~J} / \mathrm{mol}$ & Reference \\
\hline $\mathrm{S} 1$ & 0.17 & 0.74 & 0.01 & - & - & - & - & 0.04 & 0.005 & $\mathbf{1 5 9 4 8 3}$ \\
\hline $\mathrm{S} 2$ & 0.04 & 0.30 & 0.01 & - & - & - & - & 0.04 & 0.005 & 177402 \\
\hline $\mathrm{S} 3$ & 0.08 & 0.49 & 0.26 & - & - & 0.49 & - & - & - & 394163 \\
\hline $\mathrm{S} 4$ & 0.21 & 1.47 & 0.27 & - & 1.0 & 0.49 & - & - & - & 366351 \\
\hline $\mathrm{S} 5$ & 0.32 & 1.01 & 0.29 & - & 2.0 & 0.50 & - & - & - & 322450 \\
\hline $\mathrm{S} 6$ & 0.09 & 0.95 & 0.27 & 2.0 & 1.0 & 0.50 & - & - & - & 361565 \\
\hline S7 & 0.19 & 0.52 & 0.27 & 2.0 & 2.0 & 0.49 & - & - & - & 306470 \\
\hline S8 & 0.20 & 1.04 & 0.26 & 4.0 & - & 0.49 & - & - & - & 309090 \\
\hline S9 & 0.32 & 1.51 & 0.27 & 2.0 & - & 0.50 & - & - & - & 292282 \\
\hline S10 & 0.05 & 1.88 & 0.04 & - & - & 0.49 & 0.048 & 0.05 & 0.004 & 437472 \\
\hline
\end{tabular}

The austenite grain size in steels $\mathrm{S} 1$ and $\mathrm{S} 2$ has been evaluated using optical microscopy. To this end, the specimens were quenched to get final structures which enable appropriate chemical etching to reveal the boundaries of the previous austenite grains. Apart from fully martensitic states, particular structures with ferritic contours decorating the sought boundaries were employed. Both the experimental procedures and the image treatment are described in detail elsewhere $[9,25]$. According to these works, the relative error of thus determined grain size does not exceed 10\%. A similar approach [3] used for steels S3 to S9 evaluates the former grain size with about the same error. It is worth noting that the average grain diameters (equivalent area diameters, EQAD) evaluated on planar sections have been multiplied by about 1.2, following [25], in order to get actual volumetric diameters. The data on the grain growth kinetics in steel S10 have been obtained by the "laser ultrasonics" technique [11], previously verified by conventional metallographic analysis.

As follows from the employed data on the kinetics of the grain growth in austenite of the considered steels at 1000 to $1200^{\circ} \mathrm{C}$, this process develops under the retarding effect of undissolved particles. Thus, in Al-killed industrial steels S1 и S2 particles of AlN [9] do matter whereas in S10 boundary migration is affected by both $\mathrm{AlN}$ and $\mathrm{Nb}(\mathrm{C}, \mathrm{N})$ particles that corresponds to a variation of the temperature-dependent parameter $n$ in Eq. (1) in the range 3.5 to 5 [11]. In case of steels S3-S9, the parameter $n$ exceeds 4 that also the evidence of a strong barrier effect of the particles. However, there are no relevant data in [3] to clear up their type.

Values of $D_{\lim }$ substituted in Eq. (12) to implement the modeling have been found on experimental plots $D(t)$ of the grain growth as virtual asymptotes for greater time. Values of the remaining parameters of the model, ensuring the minimal average relative error in calculating the grain size, were found on the basis of experimental data only for the highest temperatures $\left(1150\right.$ and $\left.1200^{\circ} \mathrm{C}\right)$. Here, 10 of 31 data sets were employed with $D_{\lim }$ set to $350 \mu \mathrm{m}$.

Calibration involved two steps where the first one was aimed to find a set of values for combined parameter $M_{0}^{* *}\left(Y_{A E}\right)=M_{0}^{*} \exp \left(\beta_{G G}^{*} Q_{S D}\left(Y_{A E}\right) / R\right)$, as well as optimal $\alpha_{G G}$, that proved to be close to 0.5 as expected. The second step making use of $\left\{M_{0}^{* *}\left(Y_{A E}\right)\right\}$ set has determined $M_{0}^{*}=4.8 \times 10^{2} \mathrm{~m}^{3} \mathrm{~N}^{-1} \mathrm{~s}^{-1}$ and $\beta_{G G}^{*}=3.91 \times 10^{-4} \mathrm{~K}^{-1}$. Fig. 1 represents the corresponding predictions for the kinetics of the grain growth compared to relevant experimental data for some of the considered steels. As these plots evidence, the model complies with the experiment not only at high but also at relatively low temperatures.

Fig. 2 providing a comparison of the predicted to the actual grain sizes for all considered steels and temperatures confirms the model performance; indeed, the average magnitude of the relative error does not exceed $11 \%$ comparable to the measurement errors. An essential variation of the chemical compositions where the model works also should be noted; corresponding activation energies of the grain growth vary in the range where the highest $(243.7 \mathrm{~kJ} / \mathrm{mol}, \mathrm{S} 10)$ and lowest $(79.7 \mathrm{~kJ} / \mathrm{mol}, \mathrm{S1})$ values differ by about three times (Table 1$)$.

The model allows for the influence of the chemical composition of the solid solution on the mobility of the boundary in a novel way. Unlike the classical solute drag theory [21] or the up-to-date "statistical solute-pinning theory" [22,23], the considered proportionality of the growth activation energy to the activation energy of the bulk self-diffusion enables the model to get rid of numerous auxiliary parameters specific for particular alloying elements. It is remarkable that even with such a simplification, the model shows good results on steels with high contents of Mn, $\mathrm{Mo}$ and $\mathrm{Nb}$, to which the most pronounced solute drag is commonly attributed to [11]. 

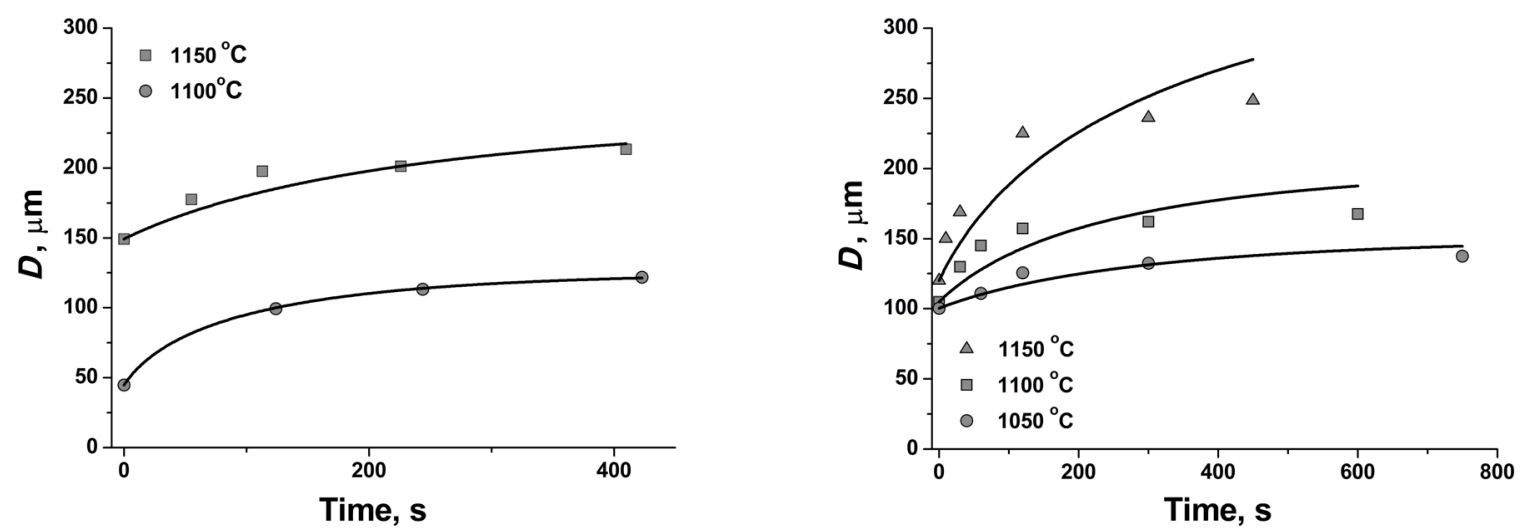

a

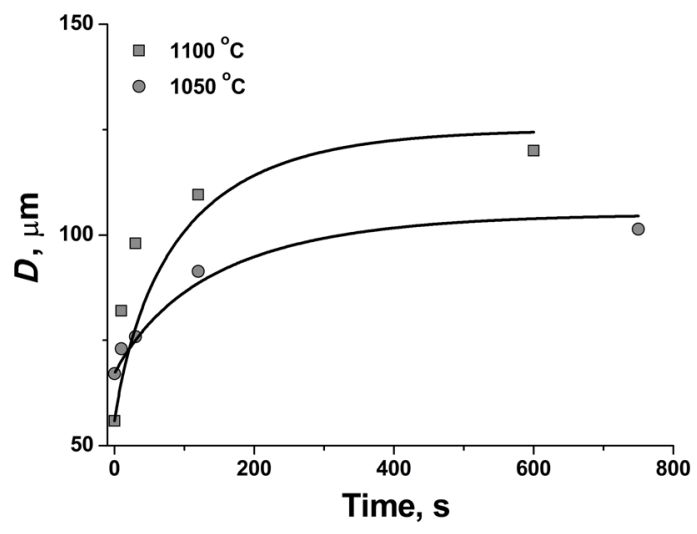

$\mathrm{b}$
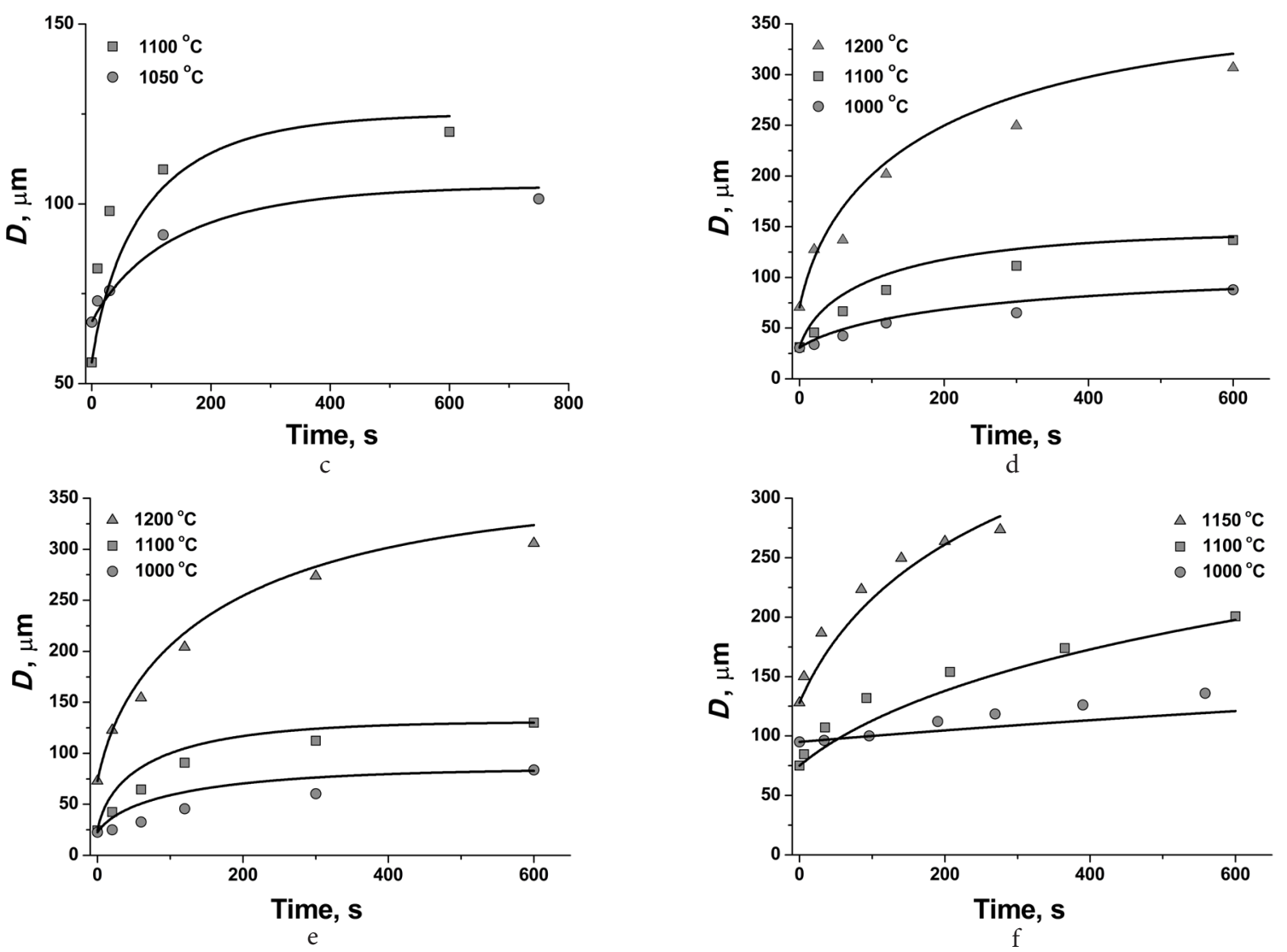

Fig. 1. Curves for grain growth kinetics according to the model and respective experimental data $[3,9,11,25]$ on steels S1 (a), S2 (b, c), S4 (d), S8 (e), S10 (f).

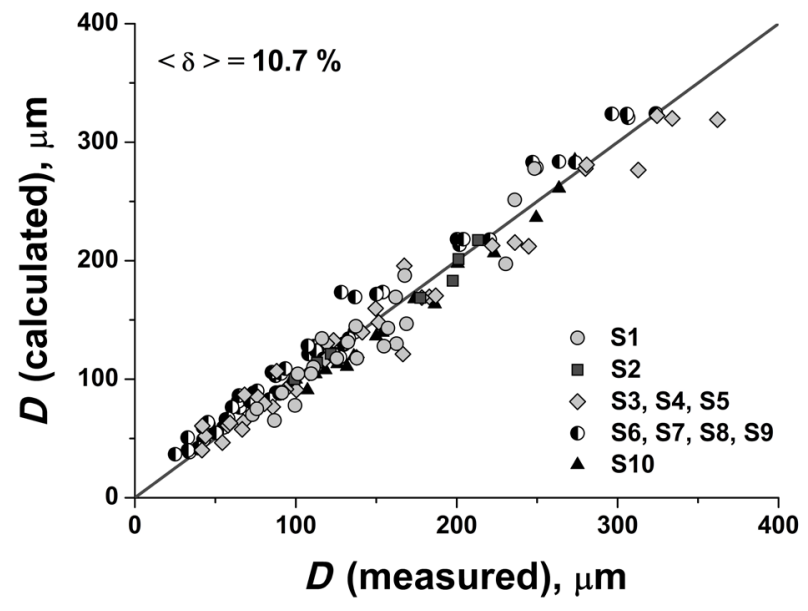

Fig. 2. Comparison of model predictions to actual grain sizes; $<\delta>$ is a magnitude of the average relative error.

\section{Conclusions}

A simple quantitative model for the grain growth kinetics in austenite has been formulated that is based on the proportionality of the activation energy of the process to the activation energy of the bulk self-diffusion, the latter being dependent on the chemical composition of the solid solution according to the previously established empirical expression. Empirical parameters of the model are fitted to relevant literature data for steels of various compositions.

The corresponding predictions comply well with the experiments on various steel compositions where the highest $(243.7 \mathrm{~kJ} / \mathrm{mol})$ and lowest $(79.7 \mathrm{~kJ} / \mathrm{mol})$ values of the calculated activation energy differ by about three times. The average magnitude of the relative error in calculating the grain size does not exceed $11 \%$ comparable to the measurement errors. 
Taking into account the influence of the chemical composition on the activation energy of grain growth, implemented in the developed model, it is possible to obtain agreement with the experiment without accounting for the solid-solution pinning of moving boundaries (the solute drag effect) requires a large number of additional empirical parameters. This result deserves further consideration from the physical viewpoint and verification on both simple carbon steels and steels with various quantities of $\mathrm{Mn}, \mathrm{Mo}$ and $\mathrm{Nb}$ which, according to literature, exert the strongest solute drag effect.

Acknowledgements. The authors are grateful to Prof. Alexander Zisman for useful discussions of the paper. This work was supported by the grant from the Russian Science Foundation (project No. 19-19-00281).

\section{References}

1. C.M. Sellars, J.A. Whiteman. Metal Sci. 13 (3-4), 187 (1979). Crossref

2. P. A. Manohar, D. P. Dunne, T. Chandra, C. R. Killmore. ISIJ Int. 36 (2), 194 (1996). Crossref

3. S. Uhm, J. Moon, C. Lee, J. Yoon, B. Lee. ISIJ Int. 44 (7), 1230 (2004). Crossref

4. M. Shome, O. Gupta, O. Mohanty. Scr. Mater. 50 (7), 1007 (2004). Crossref

5. S.-J. Lee, Y.-K.Lee. Mater. Des. 29 (9), 1840 (2008). Crossref

6. Y. Xu, D. Tang, Y. Song, X. Pan. Mater. Des. 36, 275 (2012). Crossref

7. G.-W. Yang, X.-J. Sun, Q.-L. Yong, Z.-D. Li, X.-X. Li. J. Iron Steel Res. Int. 21 (8), 757 (2014). Crossref

8. I. Andersen, Ø. Grong. Acta Metall. Mater. 43 (7), 2673 (1995). Crossref

9. M. Militzer, T. R. Meadowcroft, E. B. Hawbolt, A. Giumelli.
Metall. Mater. Trans. A. 27 (11), 3399 (1996). $\underline{\text { Crossref }}$

10. J. Moon, J. Lee, C.Lee. Mater. Sci.Eng. A. 459 (1-2), 40 (2007). Crossref

11. S. Sarkar, A. Moreau, M. Militzer, W. J. Poole. Metall. Mater. Trans. A. 39 (4), 897 (2008). Crossref

12. M. Maalekian, R. Radis, M. Militzer, A. Moreau, W.J. Poole. Acta Materialia. 60 (3), 1015 (2012). Crossref

13. H. Pous-Romero, I. Lonardelli, D. Cogswell, H. K. D. H. Bhadeshia. Mater. Sci. Eng. A. 567, 72 (2013). Crossref

14. D. Dong, F. Chen, Z. Cui. J. Mater. Eng. Perform. 25 (1), 152 (2016). Crossref

15. B. Jiang, M. Wu, H. Sun, Z. Wang, Z. Zhao, Y.Z. Liu. Met. Mater. Int. 24 (1), 15 (2018). Crossref

16. Z.-y. Liu, Y.-p. Bao, M. Wang, X. Li, F.-z. Zeng. Int. J. Miner. Metall. Mater. 26 (3), 282 (2019). Crossref

17. A. Graux, S. Cazottes, D. De Castro, D. San Martin, C. Capdevila, J.M. Cabrera et al. Materialia. 5, 100233 (2019). Crossref

18. F. J. Humphreys, M. Hatherly. Recrystallization and related annealing phenomena, 2nd ed. Oxford, United Kingdom, Pergamon Press Ltd (2004) 658p. Crossref

19. Ø. Grong. Metallurgical modeling of welding (Materials modelling series), 2nd ed. The Institute of Materials (1997) 605p.

20. J.E. Burke, D. Turnbull. Prog. Metal Phys. 3, 220 (1952). Crossref

21. J.W. Cahn. Acta Metall. 10 (9), 768 (1962). Crossref

22. E. Hersent, K. Marthinsen, E. Nes. Metall. Mater. Trans. A. 44 (7), 3364 (2013). $\underline{\text { Crossref }}$

23. E. Hersent, K. Marthinsen, E. Nes. Model. Numer. Sim. Mater. Sci. 4, 8 (2014). $\underline{\text { Crossref }}$

24. A.A. Vasilev, S.F. Sokolov, N.G. Kolbasnikov, D.F. Sokolov. Phys. Solid State. 53 (11), 2194 (2011). Crossref

25. A. K. Giumelli, M. Militzer, E. B. Hawbolt. ISIJ Int. 39 (3), 271 (1999). Crossref 